\title{
Privatização da educação experiências dos Estados Unidos e outros países*
}

\author{
STEVEN J. KLEES \\ University of Maryland, Maryland, Estados Unidos \\ D. BRENT EDWARDS JR. \\ Drexel University, Filadélfia, Estados Unidos
}

Tradução e revisão técnica de Romualdo Portela de Oliveira e Theresa Adrião

\section{RESUMO}

Objetiva-se analisar as medidas de privatização da educação adotadas nos Estados Unidos no marco do neoliberalismo, as produções elaboradas a esse respeito e o papel de indução às políticas privatistas do Banco Mundial. Para efeito de qualificação da argumentação, em alguns casos, analisa-se, à luz de produções sobre o tema, políticas de privatização adotadas em outros países.

\section{PALAVRAS-CHAVE}

neoliberalismo; privatização da educação; Estados Unidos; Banco Mundial.

* Steven Klees é professor de educação internacional e comparada no Departamento de Liderança Educacional, Educação Superior e Educação Internacional e Diretor do Programa de Pós-Graduação em Política de Educação Internacional da Universidade de Maryland. D. Brent Edwards Jr. é professor da administração educacional e educação internacional na Drexel University. Uma versão anterior deste artigo foi apresentada no Seminário Internacional de Gestão da Educação: Interfaces entre o Público e o Privado para a Oferta Educacional, Rio Claro, Brasil, 17-19 fev. 2009. Este artigo deriva de publicação anterior em Globalization, Societies, and Education (Steven J. Klees, A quarter century of neoliberal thinking in education: misleading analysis and failed policies, v. 6, n. 4, 2008, p. 311-348). Agradecemos a Susanne Clawson pelos valiosos comentários em versão anterior deste artigo. Todos os erros e omissões, entretanto, são dos autores. Comentários são bem-vindos, via e-mail para sklees@umd.edu, ou enviados para Professor Steven Klees, 2.115 Benjamin Bldg., University of Maryland, College Park, MD 20742. 


\title{
PRIVATIZATION OF EDUCATION: EXPERIENCES FROM THE UNITED STATES AND ELSEWHERE
}

\author{
ABSTRACT \\ The objective of the paper is to analyze the mechanisms of privatization \\ of education adopted in the United States, under a neoliberal framework, \\ the results of this adoption, and, more broadly, the global role of the \\ introduction of privatization policies by the World Bank. In order to \\ elaborate this argument, in some cases, an analysis of privatization policies \\ adopted in other countries is undertaken.
}

\section{KEYWORDS}

neoliberalism; privatization; education; United States; World Bank.

\section{PRIVATIZACIÓN DE LA EDUCACIÓN: EXPERIENCIAS DE LOS ESTADOS UNIDOS Y OTROS PAÍSES}

\section{RESUMEN}

El objetivo es analizar las medidas de privatización de la educación adoptadas en los Estados Unidos en el contexto del neoliberalismo, los resultados de ellas y el papel del Banco Mundial en la promoción e introducción de estas políticas de privatización. Con el propósito de sustentar mejor la argumentación, se han analizado, en algunos casos, políticas de privatización que han sido adoptadas en otros países.

\section{PALABRAS CLAVE}

neoliberalismo; privatización de educación; Estados Unidos; Banco Mundial. 


\section{ORIGENS MODERNAS DA PRIVATIZAÇÃO NEOLIBERAL}

Ao longo das décadas de 1960 e 1970, economistas do Banco Mundial (BM) recomendavam o aumento da tributação para sustentar a expansão dos serviços sociais e manter sistemas de tributação semelhantes entre os países para evitar a fuga de capitais (Gilbert; Vines, 2000; Klees, 2008). No início dos anos 1980, o BM e o Fundo Monetário Internacional (FMI) concluíram que era inviável aos países em desenvolvimento aumentar impostos. Se não se podia aumentar os impostos ou os déficits, restava transferir a educação para outros setores. Essa política é, há trinta anos, a pedra angular do neoliberalismo (Psacharopoulos; Woodhall, 1985) e denominá-la "restrição orçamentária" para o setor público a ajudou a soar razoável.

A repentina "descoberta" da "restrição orçamentária", expressa na consigna "nenhum novo imposto" disseminada pelos governos Reagan-Thatcher e mais tarde pelo primeiro Bush, é essencialmente política, e não econômica. Com os Estados Unidos controlando a política do BM e do FMI, o chamado teto orçamentátio tornou-se política institucional, dizimando serviços sociais e marginalizando ainda mais pessoas em todo o mundo. Curvar-se a essa tese é uma desonestidade entre os economistas e representa um abandono da técnica. Ainda que economistas neoclássicos discordem da ideia de aumentar impostos e gastos públicos em qualquer contexto, todos concordam que poderiam fazê-lo em circunstâncias particulares. Todos sabem que não existe "teto orçamentário", dado que tributar é uma opção política, de modo que inventar e submeter-se a essa ficção viola toda a raison d'être da economia.

Após trinta anos de estrangulamento orçamentário, ficou claro, até para o $\mathrm{BM}$, que muitos países necessitam tributar mais para financiar os serviços sociais (World Bank, 2004). Ainda que tenha passado décadas exigindo, como condição para empréstimos, a diminuição de impostos, o BM afirma poder apenas incentivar, e não exigir que os países aumentem a tributação, pois isso violaria a soberania nacional. Nesse sentido, não haveria alternativa à privatização.

\section{ENSINO PRIVADO NOS EUA}

Os Estados Unidos são o principal proponente da economia neoliberal, portanto poder-se-ia pensar que lá a privatização da educação teria avançado. No entanto, no período compreendido entre 1980 e 2007, as matrículas no setor privado diminuíram por nível de escolaridade. A matrícula pré-primária pública em 1980 era 31,7\% do total, e em 2006 atendeu a 53,5\% do total. A participação do setor privado no ensino primário passou de $11,7 \%$, em 1980, para 10,9\%; no secundário passou de 9,2\% para 8,5\%, em 2005. A matrícula em charters é uma parcela pequena, representando, em 2005,1,4\% do primário e 1,3\% do secundário (Snyder; Dillow; Hoffman, 2009).

As instituições privadas, em 1980, tinham 4\% das matrículas nos cursos superiores de dois anos e aumentaram para 5,8\% em 2007. No restante do ensino superior, o setor privado estabilizou-se em aproximadamente 32\%, em 1980/1990 
e 38,4\% ao longo das últimas duas décadas. Em síntese, desde 1980 a educação pública matricula a maioria dos estudantes no ensino superior (idem).

\section{REESTRUTURAÇÃO DA EDUCAÇÃO PÚBLICA}

Ainda que a educação nos Estados Unidos e em outros países não tenha sido privatizada, surgiram muitos experimentos e pesquisas evidenciando o impacto da privatização das atividades governamentais no ensino básico. No entanto, não há provas críveis de que alunos de escolas privadas tenham melhores resultados que alunos de escolas públicas. Isso não parece intuitivo, dado que, muitas vezes, observa-se que estudantes de escolas particulares têm escores médios mais altos em testes que alunos de escolas públicas. Considerando-se que as escolas privadas têm, geralmente, um corpo discente mais favorecido, com maiores oportunidades de aprendizagem e matriculam menos alunos com necessidades especiais ou problemas de aprendizagem, a questão que se apresenta para a política pública não é se os alunos das escolas privadas têm desempenho melhor que os de escolas públicas, mas, considerando alunos com as mesmas características, se os resultados seriam melhores.

Nos anos 1980, estudo coordenado por James Coleman (Coleman; Hoffer; Kilgore, 1982), concluiu que, controlando-se outras diferenças, os estudantes de escolas privadas superavam os de escolas públicas. Conferências de imprensa, manchetes de jornais, audiências públicas e mobilizações tentaram, com base nessas conclusões, justificar a instituição de um sistema de voucher que permitiria aos pais usar dinheiro público para enviar seus filhos a escolas privadas.

Um ano depois da divulgação do estudo, Coleman finalmente disponibilizou seus dados, e o exame de outros pesquisadores concluiu que o trabalho era de má qualidade estatística e que, controladas adequadamente as variáveis, os desempenhos acadêmicos eram semelhantes. Infelizmente, quando Coleman disponibilizou seus dados, o dano estava feito: imprensa e políticos conservadores haviam divulgado a "mensagem Coleman" de que escolas privadas eram melhores que as públicas.

$\mathrm{Na}$ década de 1990, as conclusões de Coleman tiveram novo impulso com a pesquisa "bem comercializada" de Chubb e Moe (1990). Alegando corrigir os erros de Coleman, encontraram exatamente o mesmo resultado: escolas privadas tinham melhor desempenho que escolas públicas. Campanha na imprensa encarregou-se de divulgar tais "descobertas". Como aconteceu com Coleman, os dados foram liberados um ano depois, e quase todas as análises de revisão mostraram que estudantes com as mesmas características tinham desempenho similar (Levin, 1998). Uma vez mais, nesse ínterim, os conservadores haviam disseminado uma nova onda de resultados suspeitos. Em estudos do BM para países em desenvolvimento, argumenta-se que, mesmo com desempenho equivalente, o ensino privado seria mais "rentável", por menos dispendioso, o que tornaria eficientes políticas de incentivo à transferência de alunos para escolas privadas (Lockheed; Jimenez, 1996). No entanto, em ambos os casos, os estudos de custos nos quais se baseiam subestimam os custos das escolas particulares, negligenciam a contribuição das famílias ao custo total, desconsideram que em escolas religiosas os professores recebem salários mais baixos, há outras 
formas de subsídios e que elas não aceitam estudantes que necessitariam maiores aportes (Carnoy, 1999).

Não há pois razão para crer que para a sociedade as escolas privadas seriam mais econômicas. Ao contrário, há boas razões para esperar que os gastos sejam maiores, em virtude, por exemplo, da burocracia adicional necessária à regulamentação das escolas privadas em modelos de subsídio em larga escala (Levin, 1998).

\section{ESCOLAS CHARTER E VOUCHERS}

Desde o início de 1990, nos Estados Unidos, os defensores da privatização veem as escolas charter como uma forma de introduzir a concorrência no sistema e melhorar os resultados.

Ao contrário das tradicionais escolas [públicas], cuja administração é uma burocracia executada por agências governamentais, as charter são desenvolvidas e gerenciadas por indivíduos ou grupos de pais, membros da comunidade, professores ou organizações de gestão da educação. (Renzulli; Roscigno, 2005, p. 345)

Apesar do financiamento público e de serem consideradas escolas públicas, às escolas charter concede-se autonomia "da maioria dos regulamentos estaduais e locais e das convenções burocráticas [...] sendo obrigadas a defender seus contratos com os conselhos escolares sob risco de serem fechadas" (idem, ibidem). A ideia é a de que tal autonomia e flexibilidade permitiriam a essas escolas focar no desempenho dos alunos e responder às exigências dos pais, por meio de currículos e programas especializados, orientação religiosa e serviços complementares. No entanto, informações desiguais, custos de transporte e outras barreiras à matrícula influenciam as características de seus alunos e desafiam a noção de concorrência em que tal esquema de escolha se assenta.

Pesquisas sobre a eficácia das escolas charters têm crescido (Lubienski; Lubienski, 2006). Estudo nacionalmente representativo abordou preocupações em matéria de controles simultâneos para as variáveis aluno e nível de escola, concluindo que:

Após o controle das diferenças demográficas, os resultados em matemática mostraram que não havia diferenças estatisticamente significativas entre escolas públicas, charters e privadas e, na quarta série, os resultados das escolas públicas era significativamente melhores que as demais. (idem, p. 679-680)

Esses resultados desafiam a noção de que a autonomia das charters e os arranjos para a escolha de escolas produzem maior efeito. Ademais, charters são, em geral, administradas privadamente, às vezes por grandes corporações, o que constitui outro mecanismo de privatização (Fabricant; Fine, 2012)

Mesmo em menor escala, outros países têm experimentado modelos como as charters. No Reino Unido, por exemplo, o programa das escolas-academias permite a gestão privada (por indivíduos, empresas ou grupos religiosos) de cerca de trinta 
escolas públicas secundárias. Até o momento, não há evidências de que a gestão privada seja mais eficaz que a pública (Machin; Wilson, 2009). Em Bogotá, Barrera-Osorio (2009) afirma que, para 25 escolas financiadas pelo poder público e geridas por escolas privadas de elite, há pequeno efeito positivo nas notas dos alunos, mas deficiências metodológicas do estudo indicam o contrário (Klees, 2010).

Os vouchers geralmente tiram dinheiro da educação pública para dá-lo a famílias que desejam enviar os filhos a escolas privadas. Parte fundamental de sua lógica baseia-se na suposição de que alunos do ensino privado cursariam uma escola melhor e que a concorrência e a disciplina do mercado levariam, necessariamente, as escolas a serem mais inovadoras e sensíveis às demandas da comunidade. Nos Estados Unidos, estudos sobre os processos educativos desenvolvidos em escolas públicas e privadas não sustentam essa hipótese, pois mostram que, para escolas com alunos com características semelhantes, o processo educacional e o grau de introdução de programas inovadores são muito semelhantes (Carnoy; Rothstein; Benveniste, 2003). Estudo sobre inovação em programas de escolha de escola na Inglaterra, País de Gales, Estados Unidos e na Nova Zelândia concluiu que previsões

sobre a concorrência e a escolha, não são em grande parte cumpridas [...] De fato, intervenções por burocracias públicas muitas vezes têm conseguido estimular a inovação em sala de aula, enquanto mecanismos de mercado parecem contribuir para sua padronização. (Lubienski, 2001, p. 1)

Ao contrário, exemplos de programas inovadores, considerados muitas vezes como modelos pelo próprio BM, vêm do setor público, como o Escuela Nueva, na Colômbia.

Os críticos apontam que os vouchers aumentam a desigualdade, uma vez que subsidiam-se famílias mais ricas, que já enviam seus filhos para escolas particulares. Se nos Estados Unidos há razões para famílias de baixa renda quererem vouchers para acessar escolas consideradas melhores e tal opção pode ser considerada individualmente racional, como opção de política pública não é, pois é provável que o financiamento disponível seja limitado, permitindo a poucas famílias de baixa renda enviar os filhos a escolas privadas, especialmente porque, em geral, o voucher cobre apenas parte da matrícula. Complementarmente, à medida que aumentem os vouchers, as escolas públicas tornar-se-iam repositório de crianças mais pobres, de estudantes considerados "difíceis de educar" e de pessoas com necessidades especiais. Além disso, o voucher diminuiria a atenção às escolas públicas, pois se presume que a competição resolveria os problemas sem custos adicionais (Levin, 1998).

A principal resposta às críticas de que esses sistemas agravam as desigualdades é a proposição de vouchers direcionados a famílias de baixa renda. Houve quatro experiências significativas com esse enfoque nos Estados Unidos. Em Milwaukee (Wisconsin) e Cleveland (Ohio), o dinheiro público está sendo usado para que um número limitado de famílias envie seus filhos a escolas privadas. $\mathrm{O}$ terceiro, financiado privadamente por fundações conservadoras pró-voucher, ocorre em Dayton (Ohio), Nova York e Washington, DC. O quarto experimento é público, aprovado pelo Congresso dos Estados Unidos e também implantado em Washington. 
Os resultados das avaliações dos quatro programas são bastante controversos. (Viadero, 1998). Um pesquisador em particular, Paul Peterson, da Universidade Harvard, afirma que, em todos eles, os alunos que receberam vouchers pontuaram mais em testes de desempenho que estudantes com características semelhantes matriculados em escolas públicas (Howell et al.,2000). Em contrapartida, os avaliadores dos programas de voucher com financiamento público em Cleveland e Milwaukee constatam que alunos que receberam vouchers não apresentam melhores resultados que alunos de escolas públicas (Metcalf, 1998). Peterson reanalisou os dados para esses casos e concluiu que em ambos há erros. Quando "corrigidos", alunos que usavam vouchers em ambas as cidades tiveram resultados melhores (Viadero, 1998). Os avaliadores criticados, contra-argumentaram que a análise de Peterson estava errada, pois simplesmente "cozinhava" dados para produzir resultados que sustentavam seus preconceitos (Metcalf, 1998, p. 12).

No entanto, como em Coleman, Chubb e Moe, os resultados de Peterson tiveram muita cobertura da mídia, e análises posteriores levantaram dúvidas sobre a metodologia do estudo e seus resultados (Kruger; Zhu, 2004), e um dos membros da equipe de Peterson o criticou publicamente por tirar conclusões não sustentadas pelos dados (Myers; Pfleiderer, 2000).

Resultados semelhantes foram encontrados na análise do programa Escolha da Escola, de Washington, primeiro e único programa de vouchers financiado pelo governo federal nos Estados Unidos. Identificou-se, por uma avaliação de três anos, com amostra aleatória, que poucos alunos melhoraram seus resultados em testes de leitura (e nenhum em testes de matemática), e os que melhoraram foram os mais favorecidos (Wolf et al., 2009), ou seja, os estudantes desfavorecidos, para quem o programa se destinava, não se beneficiaram significativamente em leitura ou matemática. Tais resultados desafiam a crença de que mais autonomia e competição reduzem a distância entre estudantes com alto e baixo rendimento.

Vale lembrar que a experiência com vouchers nos Estados Unidos ocorreu nos anos 1950, após a Suprema Corte ordenar que o sistema escolar deveria acabar com a segregação racial. No Sul, alguns distritos escolares responderam à decisão fechando escolas públicas e dando vouchers a todas as crianças. Isso permitiu a famílias brancas continuar com comportamento racista, enviando seus filhos para escolas privadas, apenas de brancos.

Em vista disso, não acreditamos que a privatização do ensino primário e secundário garanta uma educação que leve à justiça, à democracia, ou a qualquer das externalidades necessárias para uma sociedade eficiente e equitativa.

Supreendentemente, apesar de mais de um quarto de século de retórica privatizante na educação, há poucas reformas de grande amplitude. As grandes reformas dos governos neoliberais no Reino Unido nos anos 1980 e na Nova Zelândia nos 1990 concentraram-se principalmente em promover maior escolha entre escolas públicas. A Holanda, apontada como exemplo de privatização - pois escolas privadas são financiadas da mesma maneira que as públicas, ainda que sejam proibidas de cobrar mais que o subsídio estatal -,é um caso específico que atendeu a compromissos históricos e políticos entre protestantes e católicos. Desempenho ou aumento da eficiência não eram o problema, dado que as escolas privadas são 
altamente reguladas. No entanto, o BM ainda a cita como exemplo bem-sucedido de escolha de escola que favorece "os mais pobres".

Nos países em desenvolvimento, há dois exemplos de voucher, no Chile e na Colômbia. O Chile, vitrine das políticas econômicas neoliberais, implantou vouchers para o ensino básico no início de 1980, sob a ditadura de Augusto Pinochet. Hoje, cerca de um terço dos alunos do ensino primário fazem uso de vouchers. Pesquisas indicam que estudantes de escolas públicas se saem melhor em testes de desempenho após o controle de nível socioeconômico, ainda que as escolas privadas, ao atenderem apenas alunos de elite, tenham o trabalho facilitado e reduzam o desempenho médio das escolas públicas pelo mecanismo de seleção de estudantes (Belleï,2009). O Chile também mostrou outros efeitos deletérios dos vouchers. Em virtude da repressão durante o regime de Pinochet, os vouchers foram usados para neutralizar os sindicatos docentes, na medida em que a contratação e demissão de professores foram transferidas para a esfera local e privada, sem qualquer proteção.

$\mathrm{Na}$ Colômbia, vouchers financiaram escolas privadas impedidas de cobrar dinheiro adicional dos pais. Mesmo assim, famílias com maiores níveis de renda foram privilegiadas. Em 1990, 28\% das famílias dos 40\% mais pobres e $75 \%$ das famílias dos 20\% mais ricos enviaram seus filhos para escolas voucher (Carnoy, 1998). Mesmo que não tenham melhores resultados em testes, o acesso aos vouchers pelos mais ricos gera retorno indireto, ao permitir o agrupamento de pares com resultados mais altos e aumentar a probabilidade de aprendizagem e de acesso à educação superior.

Considerando o exposto, é provável que o aumento da privatização do ensino básico aumente as desigualdades e as ineficiências, pois os mais ricos adquiririam vantagens adicionais.

\section{MODELOS PRIVADOS DE GESTÃO ESCOLAR}

Outra faceta importante da privatização na educação é a transferência de modelos de gestão e avaliação da área de negócios para a racionalização da alocação de recursos.

Uma característica da retórica neoliberal é que o financiamento dos serviços sociais deve basear-se em casos de sucesso atestados por resultados mensuráveis. Basear o financiamento no grau em que se alcance resultados desejáveis parece sensato e racional para a tomada de decisões. No entanto, essa "ajuda com base em resultados" torna-se uma forma de privatização dos serviços educacionais.

Nesta seção, revisamos cinco programas ou orientações adotados nos Estados Unidos relacionados ao financiamento baseado em resultados, indicando algumas das razões para seu fracasso. As duas primeiras - Sistemas de Orçamento Programa (Program Planning Budgeting Systems - PPBS) e Orçamento por Desempenho aplicadas a todas as atividades do setor público, e as três últimas - Pagamento por Mérito; Testes Padronizados e Contratos por Desempenho -, à educação.

Um precursor do financiamento baseado em resultados nos Estados Unidos foi o Sistema de Orçamento Programa (SOP), proposto em 1960 pelo presidente Lyndon Johnson para o governo federal e que não logrou ser implantado. Tal sistema 
foi concebido como forma de redesenhar orçamentos governamentais, facilitando a avaliação de políticas e programas do setor público (Miller; Hildreth; Rabin, 2001).

O SOP propunha-se a alterar a forma de elaboração dos orçamentos a fim de refletir os custos de cada programa. Orçamentos convencionais são, geralmente, inúteis para análise de custos, pois combinam as entradas de maneira que estas não se separam, agrupam uma variedade de programas no mesmo orçamento e usam convenções contábeis que não refletem o valor dos recursos. Se os orçamentos fossem reestruturados para revelar claramente os custos econômicos dos diferentes programas, estes poderiam ser examinados em relação ao sucesso do programa na consecução dos objetivos, e programas diferentes poderiam ser comparados.

Para Klay (1987, p. 62), o SOP seria o "zenith das reformas orçamentárias que se propõem a ter como base o que [...] tem [sido] chamado de 'racionalidade econômica". Entretanto, na literatura, o SOP é um caso de fracasso frequentemente citado (Miller; Hildret; Rabin, 2001).

Os departamentos governamentais não sabiam como e não tiveram incentivos para implantar o sistema. Orçamentos convencionais são construídos de modo que sirva a outros fins que não à avaliação de programas, fins institucionalmente arraigados que servem a uma variedade de interesses burocráticos e são politicamente invioláveis. Mesmo com o presidente dos Estados Unidos tentando, as barreiras não foram superadas. Tal proposta não pode ser bem-sucedida porque os resultados não podem ser relacionados a insumos e aos custos de um programa específico, razão pela qual não faz sentido premiar a produção de sucesso, sem ideia do programa responsável por isso e de seus custos.

Outras reformas semelhantes foram introduzidas nos Estados Unidos: "Gestão por Objetivos" e "Orçamento Base-Zero" (idem). A partir de 1990, o orçamento baseado em resultados ou por desempenho tornou-se obrigatório em muitas agências estaduais e federais.

Se o financiamento por desempenho parece razoável e racional em abstrato, apresenta maiores problemas que o SOP. Primeiro, porque se concentra em resultados mensuráveis. Como a maioria dos programas têm muitos resultados que podem ser medidos, ainda que insatisfatoriamente, o orçamento baseado em resultados é subutilizado.

Em segundo lugar, a implantação desse tipo de orçamento dobrou-se às lições do SOP: se os orçamentos não refletem os custos do programa, então, mesmo que os resultados sejam medidos de maneira sensata, é impossível isolar os programas que melhoraram ou declinaram; logo, é impossível dizer quem ou o que deve ser recompensado (idem).

Terceiro, os orçamentos por desempenho são elaborados antes da realização das despesas. Medidas de desempenho tornam-se muitas vezes listas de desejos, de metas escolhidas apenas para a satisfação da agência doadora, que as impõem como condição de financiamento (idem).

Quarto, os orçamentos por desempenho podem ser menos úteis que os convencionais, pois muitas vezes se transformam em bizarras tentativas de separar as despesas previstas por metas de resultados. Se um programa foi pensado para produzir três resultados, por exemplo, a melhoria em matemática, leitura e escrita, 
cada item do orçamento seria dividido em cada um desses objetivos. O salário de um professor, de US $\$ 20.000$, poderia ser dividido em US $\$ 10.000$, US $\$ 6.000$ e US $\$ 4.000$, divisão suposta como a parte do trabalho do professor que afeta cada resultado. $\mathrm{Na}$ prática, determinar uma base razoável para tal divisão não é nem remotamente possível, e tais divisões se tornam arbitrárias e confusas.

Finalmente, dado que os custos são realizados para cada agência financiadora, não aparecem os custos do programa para outras agências e os custos diretos e de oportunidade aos usuários. Comparar programas com uma análise muito parcial dos custos e dos resultados é, do ponto de vista da economia, ineficiente e não faz sentido.

Nos Estados Unidos, avaliações de orçamento por resultados mostram que estes pouco incidem sobre a intenção original de racionalização do processo decisório. Em pesquisa com diretores de orçamento de cinquenta estados, Jordan e Hackbart (1999, p. 13) concluem que "a performance pode afetar a aparência e a preparação do documento orçamental, mas o resultado em termos de financiamento não é significativamente afetado". Em dez de catorze estados que adotaram o orçamento baseado em resultados, apenas $3 \%$ ou menos do orçamento de uma agência pode ser considerado correlacionado ao seu desempenho. Nota-se que o próprio BM não pratica o que prega: nunca se propôs a realizar um orçamento baseado em resultados, mas o está impondo em seus financiamentos.

Um bom exemplo para entender o fracasso de propostas de financiamento por resultados é o pagamento por mérito implantado nos Estados Unidos em meados de 1980. Nesse modelo, professores recebem um aumento salarial com base no aumento da pontuação nos testes. O problema principal é que tais programas geralmente têm propostas que não fazem sentido do ponto de vista de uma avaliação racional, e os resultados são prejudiciais a professores e estudantes. Do ponto de vista da economia, o pagamento por mérito para professores é tão injusto quanto ineficiente, por muitas razões.

Muitos aspectos afetam os resultados: educação e atenção dos pais, renda familiar, oportunidades de aprendizagem fora da escola, aspirações, atitudes, esforços em trabalhos de casa, escolaridade prévia, acesso a computador em casa, características dos pares, disponibilidade e uso de recursos, como bibliotecas e laboratórios, tamanho das turmas, organização escolar etc. Esses fatores afetam mais os resultados que a ação do professor (Hanushek, 1986). Portanto, adotar o pagamento por mérito é injusto com os professores, pois não há razão para acreditar que ganhos ou perdas reflitam apenas o ensino, e é ineficiente, pois muitos professores ineficientes cujos alunos melhoram por outros fatores receberão recompensas, e muitos bons professores cujos alunos melhoraram pouco por outros fatores não.

Os economistas há muito tempo tentam separar o efeito causal de cada entrada de ensino sobre o desempenho do aluno por meio do que chamamos função de produção educacional para chegar ao "valor agregado" pelo professor (idem). Em teoria, esses modelos matemáticos poderiam isolar a eficácia de um professor de características determinadas por "controles" para os efeitos de todas as outras entradas. No entanto, as condições teóricas necessárias para tal realização são completamente irrealistas. Na prática, dada a complexidade dos processos de aprendizagem e contexto, a ideia de determinar o efeito causal de cada entrada, 
como professores, tem se provado impossível (Klees, 2008). Quatro décadas de tais estudos não resultaram em achados consistentes sobre a eficácia dos insumos educacionais (Hanushek, 1986, 2004).

A gratificação do professor por um bom ensino não é o que está em pauta aqui. Questiona-se a ideia de que a introdução da proposta possa ser feita de maneira mecânica, mensurável e estritamente científica. Uma questão que cabe é: Por que aqueles que recomendam esquemas de pagar mecanicamente por mérito aos outros não o fazem para si mesmos? Por que não há um esforço para haver mérito nos esquemas de pagamento de funcionários do BM com base no percentual, por exemplo, em que seu trabalho reduz a pobreza?

A questão-chave de todas as formas de financiamento baseadas em resultados tem sido examinar os resultados. Cada vez mais se tem focado apenas no resultado em testes padronizados. Essa ação tem sido desastrosa para a educação. Testes, não importa como sejam concebidos, são medidas muito estreitas dos resultados desejados. A ênfase sobre eles levou a um ensino direcionado para o teste, desanimando igualmente professores e pais (Bracey, 2002; Kohn, 2000).

Hoje, nos Estados Unidos, qualquer tema não contemplado nos testes, como arte, música ou educação física, recebe menos tempo de ensino. Alunos do ensino fundamental têm pouco ou nenhum lazer. A pressão sobre os professores e diretores é tão forte que às vezes idas ao banheiro são racionadas para que não se perca conteúdo. Estudantes doentes são mantidos em sala de aula, e muitos professores e diretores têm sido apanhados auxiliando os alunos nas provas para elevar as notas. O moral dos professores e diretores nessa situação é o pior possível (Kohn, 2000). Os recursos gastos com os testes são enormes. As pressões sobre os estudantes têm causado ansiedade generalizada e problemas mentais e comportamentais (idem). Além disso, nos Estados Unidos, não há evidências de que o esforço de mais de uma década nessa direçaõ tenha feito alguma diferença no desempenho escolar. Por essas razões, cresce internamente a resistência aos testes padronizados, enquanto concomitantemente, e como em outras ocasiões, começa-se a exportá-los para os países em desenvolvimento (Kohn, 2000; Nichols; Glass; Berliner, 2005).

Outro problema é identificar escolas meritórias. Na década de 1980, legisladores da Flórida aprovaram remuneração por mérito para escolas. Sabe-se que os ganhos nos escores de uma escola são significativamente mais influenciados por fatores extras que intraescolares. Pesquisa, em cada um dos 67 distritos escolares do estado, reconhecendo esse problema adotou a abordagem da função educativa de produção, controlando algumas das variáveis consideradas mais relevantes, sobre as quais as escolas dispunham de dados, por exemplo, percentual de alunos de baixa renda, composição racial etc. Como acontece em pesquisas similares, percebeu-se que, alterando as variáveis controladas, mudavam-se completamente as escolas com bons resultados. Não havia, portanto, base para decidir qual combinação de variáveis seria utilizada para controlar os resultados. Muitos funcionários envergonharam-se de definir o prêmio em dinheiro para as escolas, porque não havia nenhuma maneira válida para explicar em que bases estavam sendo ou não recompensadas. $\mathrm{Na}$ verdade, não havia maneira válida de medir o que os economistas chamam de "valor acrescentado" (Amrein-Beardsley et al., 2013). 
Mesmo havendo uma maneira válida de determinar se uma escola é meritória, o que deve ser feito? O que fazer com escolas de baixo desempenho? Na prática, há uma variedade de respostas para esse dilema, o mais comum é uma espécie de processo em dois estágios: pequena cenoura/grande sanção, pelo qual uma escola recebe, inicialmente, um aviso de que deve melhorar com, talvez, algum recurso adicional. Se não houver melhora, pode sofrer intervenção por parte do distrito, ou, no caso de um distrito, intervenção por parte do estado (substituição de professores, diretores e outros administradores). Não há evidências de que tais intervenções tenham qualquer efeito (Malen et al., 2002).

A ideia de contratos por desempenho é periodicamente "redescoberta", tanto no setor público quanto no privado. Na década de 1970, nos Estados Unidos, como parte de uma era anterior de respostas simplistas a questões de responsabilização, contratos por desempenho em educação tiveram uma curta e malsucedida história. Em virtude dos baixos níveis de escolaridade em escolas com crianças desfavorecidas, algumas cidades, como Gary, no estado de Indiana, contrataram empresas privadas para gerenciar algumas escolas. Isso gerou forte oposição de pais e professores, não melhorou o desempenho e não durou muito tempo. Na expressão de Bracey (2002, p. 76), nessa anterior encarnação de contratos por desempenho, "os resultados dos testes eram inventados, e a coisa toda naufragou".

Desde meados dos 1990, outra época de respostas simplistas para a responsabilização, contratos por desempenho com empresas privadas ressurgiram em pequena escala e pelas mesmas razões. Atualmente, a principal empresa privada com fins lucrativos a assumi-los é a Edison Schools, contratada pelos distritos escolares para operar escolas de baixo desempenho em várias cidades em todo o país. Embora a Edison tenha comercializado agressivamente seus serviços desde a fundação, em 1991, manteve-se pequena por muitos anos, até que o clima pró-privatização promoveu seu envolvimento com cerca de mil escolas em todo o país. Enquanto reivindica sucesso acadêmico, as avaliações externas indicam que seus alunos não apresentam melhores resultados que os de escolas públicas (Bracey, 2002; Levin, 2006; Molnar, 2001; Saltman, 2000).

A Edison visa a ter lucro, mas suas perdas foram calculadas em US $\$ 600$ milhões (Levin, 2006), ainda assim, seus executivos vão bem (Bracey, 2002). Em 1999 , seu fundador, Chris Whittle, declarou acumular cerca de US $\$ 300.000$ por ano, receber um milhão de dólares por outros serviços e ter opções de ações na companhia de US $\$ 32$ milhões. Sua participação na propriedade da Edison foi avaliada em cerca de US $\$ 200$ milhões, levantando questões sobre os reais interesses da privatização.

Com o modelo de contratos por desempenho tem-se um forte e claro mecanismo para testar a capacidade de o setor privado responder adequadamente no campo educacional. Da organização privada contratada exige-se um, e somente um, simples objetivo: melhorar o desempenho em testes. E, mesmo assim, esta é incapaz de fazê-lo melhor que as escolas públicas! Isso é verdade não apenas para a Edison, mas para empresas privadas em educação em todos os Estados Unidos (EUA General Accounting Office, 2003). Vale ressaltar ainda que as escolas públicas tentam, concomitantemente, melhorar o desempenho, responder a outros objetivos demandados por pais e comunidades, que muitas vezes envolvem ações 
de bem-estar, saúde, segurança etc. Considerando esse quadro, por que achar que o setor privado pode oferecer algo melhor para a educação?

\section{CONCLUSÕES}

Por décadas, políticas privatistas têm causado danos incalculáveis a crianças e adolescentes, lesados no acesso à escolaridade em virtude de cortes orçamentários. Não há evidências de que charters ou vouchers melhorem os resultados ou a eficiência das escolas, mas há evidências de que os vouchers exacerbam desigualdades. Argumentos de apoio a financiamento baseado em resultados podem parecer superficialmente sensíveis, mas ignoram quatro décadas de prática que evidenciam seu fracasso.

Antes de 1980, o BM e outros organismos internacionais recomendavam maiores investimentos em educação e outros serviços sociais. Tais recomendações cessaram quase da noite para o dia, quando o BM adotou a retração dos gastos governamentais e a ideologia do teto orçamentário. $\mathrm{O}$ tema do Relatório do BM de 1980 foi a "gestão", repentinamente transformada em problema-chave para os serviços sociais. Por mais de um quarto de século, quase toda reforma neoliberal foi um mix de medidas sobre a gestão: reorganização, reestruturação, reengenharia, gestão do conhecimento, pagamento por mérito, leis de reforma do serviço civil, participação da comunidade, descentralização, aumento nas testagens, vouchers, privatização, ajuda com base em resultados etc. Quase nenhuma reforma educacional recomendou mais investimentos. Ao contrário, em muitos casos, o objetivo explícito da reforma era cortar custos. Ocasionalmente, recomendava-se gastar um pouco mais em livros didáticos, na formação contínua de professores, na educação das meninas, mas, na prática, quase não foram alocados novos recursos (Klees; Samooff; Stromquist, 2012).

Não é à toa que a Educação para Todos (EPT) não tenha feito progressos consideráveis. Para fornecer uma educação básica adequada para todas as crianças do mundo, requer-se um comprometimento significativo de recursos. Não é de estranhar que, em meados dos 1990, parte das metas do pacto EPT previstas para 2000 foi adiada para 2015. Em Dakar 2000, em reunião para avaliar e acompanhar os dez anos anteriores da EPT, em resposta à questão do financiamento, Wolfensohn, então presidente do BM, anunciou que este destinaria mais recursos, de modo que nenhum país seria impedido de alcançar as metas por limitações financeiras. Mas isso não ocorreu, e as metas previstas para 2015 não serão atingidas, constatação anterior à recente crise econômica global (Marphatia; Archer, 2005; World Bank, 1999, 2004, 2011).

O que se percebe ao analisar a agenda neoliberal para a educação é a pouca referência à sua substância, ao que realmente acontece na sala de aula. $\mathrm{O}$ mais próximo disso é a atenção dada aos professores, os quais são vistos, em geral, como um problema laboral (Klees; Samoff; Stromquist, 2012; World Bank, 1999, 2011).

Além disso, ao se generalizar ideias de que não há alternativa, que o essencial são os resultados, e não os insumos, que os professores são os inimigos, que os governos são incompetentes e corruptos e que, por isso, devemos privatizar e cobrar 
taxas aos usuários para acesso a serviços sociais, generalizam-se análises enganosas e politicamente descontextualizadas. Em um mundo onde alguns países gastam US $\$ 100$ ou menos por aluno/ano na escola primária, esse argumento é obsceno. As diferenças entre recursos gastos com crianças favorecidas e desfavorecidas são enormes (Reimers, 2000), até mesmo em países ricos, como os Estados Unidos, cujos efeitos sobre crianças negligenciadas resultam no que Kozol (1992) chamou de "desigualdades selvagens".

Alternativas eficazes às políticas neoliberais, em sua maioria, requerem dispêndio de recursos adicionais. Nos Estados Unidos, por exemplo, até a última onda de obsessão por testes padronizados, houve grande interesse e extensa disseminação no uso dos portfólios. ${ }^{1}$ Como alternativa a esquemas mecânicos de mérito, podem-se tratar professores como profissionais e desenvolver um sistema de avaliação que reflita as complexidades do ensino e considere a avaliação profissional, principalmente pelos pares. Nos Estados Unidos, tais sistemas operam, hoje, em alguns distritos escolares, o que exige confiança e investimento nos professores, em lugar de controle e punição (Darling-Hammond; Bransford, 2005).

Em contrapartida, reforço à gestão não significa a simples introdução de modismos como modelos de gerenciamento emprestados do setor privado ou de medidas de descentralização, muitas vezes limitadas à transferência da responsabilidade pelo fracasso educacional e sem recursos adicionais para a construção de alternativas. Na educação, precisamos de uma gestão local participativa, integrada por professores, pais, alunos com acesso a recursos suficientes para pôr em prática a mudança. Também precisamos de estruturas de governança regionais e nacionais participativas, que garantam equidade e que reflitam as necessidades sociais mais amplas, os direitos dos professores e outros objetivos coletivos (Hahnel, 2005). No lugar da recuperação de custos, necessita-se de novos mecanismos de fornecimento de recursos adicionais: um substancial alívio da dívida dos países pobres, substituindo as limitadas ações tomadas até agora pelos organismos internacionais, seria uma alternativa.

É preciso um conjunto muito maior de fundos de desenvolvimento e uma abordagem menos técnica e mais participativa para sua distribuição, orientada diretamente para a promoção dos direitos humanos e da justiça social. Como modo de promover muito mais substancialmente a transferência Norte-Sul, seria preciso um acordo global que orientasse a complementação das transferências pela expansão do imposto de renda progressivo nos países em desenvolvimento, articulada a certa uniformidade tributária entre os países, para inibir a fuga de capitais.

Em vez de pagar para ir à escola, os estudantes pobres deveriam receber bolsas pela frequência à escola, condição necessária para compensar as famílias pelos custos diretos e de oportunidade que dificultam a permanência na escola. O BM e outros fizeram experiências com bolsas desse tipo, que foram bem-sucedidas, por

1 Conjunto de materiais e atividades integrado por produções artísticas, artigos escritos, evidências de proficiência matemática e usado como forma principal de avaliação dos resultados educacionais (Barton; Collins, 1997). 
exemplo, na manutenção de meninas na escola. No entanto, a maioria dos programas de bolsas permanece em pequena escala. Os mais abrangentes e caros, como o Oportunidades, do México, e o Bolsa Família, no Brasil, ainda que elogiados pelo $\mathrm{BM}$, não são por ele considerados políticas públicas essenciais para o alcance das metas dos Objetivos de Desenvolvimento do Milênio e de Educação para Todos (World Bank, 2004, 2011).

Em vez de privatização, melhorar as escolas públicas. Talvez o mais importante seja abandonar a crença ridícula de que exista solução sem custo para os problemas educacionais. Estimativas dos custos para proporcionar uma educação primária para todas as crianças no mundo, ainda não atendidas, chegam a US\$16 bilhões por ano (UNESCO, 2012). Esses valores estão provavelmente subestimados, mas, mesmo assim, representam menos de um décimo de $1 \%$ do produto interno bruto (PIB) mundial.

É óbvio aquilo de que os estudantes precisam: professores bem formados, pagos com o suficiente para que lhes seja permitido dedicar-se em tempo integral ao ensino; bons livros e outros recursos didáticos; turmas suficientemente pequenas para que os professores possam ensinar e incentivar o amor e o interesse pela aprendizagem; edifícios que ofereçam ambiente propício à aprendizagem. Se isso não estiver no horizonte, "EPT" ou a educação como um direito continuará a ser uma falsa promessa.

A esse respeito, é instrutivo olhar para os países ricos. Nos Estados Unidos, a sociedade mais rica do mundo, vergonhosamente, mais de um quarto das crianças crescem na pobreza (Kozol, 2012). Nas duas últimas décadas tem sido comercializada a ideia absurda de que não faz sentido colocar mais dinheiro em um sistema educacional já "falido". Para a classe média, o sistema não está quebrado. Crianças de classe média em escolas públicas dos Estados Unidos sempre tiveram bom ensino e continuam a tê-lo. O sistema falhou apenas para aqueles cujas famílias estão lutando para sobreviver e, por isso, muito mais recursos são necessários na educação, se quisermos oferecer oportunidades reais para o grande número de crianças marginalizadas (Bracey, 2002).

Experiência com interessante lição ocorreu em 1998 nos Estados Unidos. A Merrill Lynch elaborou um programa para escolas com crianças marginalizadas em 250 cidades, pelo qual pagaria faculdade às crianças matriculadas na primeira série que terminassem o ensino médio. Inicialmente, a empresa imaginou que essa promessa, combinada com um pouco de tutoria, seria suficiente para lograr o objetivo. No entanto, logo percebeu que as crianças precisavam de muito mais ajuda e que seria necessário investir muito mais recursos. Fez isso por doze anos: seus funcionários investiam parte de seu tempo no acompanhamento individual de alunos, em trabalhos nas salas de aula e em outras atividades. Contratou pessoal em tempo integral para trabalhar com as crianças e fornecia ajuda adicional às famílias empregos, assistência médica, acampamentos de verão e muito mais. Mais de $90 \%$ dessas crianças concluíram o ensino médio (Chase, 2000; Merrill Lynch, 2000).

Essa história não é uma exceção. Esforços intensivos, turmas pequenas, muita atenção individual, um adulto que acompanhe a criança em longo prazo, ajuda com os trabalhos e ensino superior acessível podem transformar a vida de uma criança 
(Schorr, 1990). Privatização e caridade não farão isso em larga escala. Sabemos o que precisamos fazer para superar esse estado de coisas, isso não requer mais pesquisas. Ocorre que não há vontade política nessa direção.

Para concluir, é importante ressaltar que o neoliberalismo não passou inconteste. ONGs engajam-se no que tem sido chamado de "cooperação crítica" com o BM, o FMI e outras agências, na esperança de que possam introduzir mudanças significativas no interior dessas instituições (Fox; Brown, 1998). Tais grupos são, por vezes, auxiliados por funcionários daquelas instituições que compartilham algumas das críticas e se veem dispostos a trabalhar para mudanças desde seu interior. Além disso, observa-se o aumento no confronto - por grupos e movimentos sociais, povos indígenas, sem-terra, ambientalistas, estudantes, trabalhadores e outros (Mundy; Murphy, 2001) e os organismos de financiamento. Registra-se ainda o desenvolvimento de modelos alternativos que mostram uma série de novas possibilidades (Hahnel, 2005). Passado mais que um quarto de século, insistir no acúmulo de análises enganosas e políticas fracassadas apenas reforçará essas contestações.

\section{REFERÊNCIAS}

Amrein-Beardsley, A.; Collins, C.; Polasky, S.; Sloat, E. Value-Added: what America's policymakers need to know and understand. Education Policy Analysis Archives, Washington, DC: ASU, v. 21, p. 1-14, 2013.

Barrera-Osorio, F. The concession schools of Bogotá, Colombia. In: Chakrabarti, R.; Peterson, P. (Eds.). School choice international: exploring public-private partnerships. Cambridge, MA: MIT Press, 2009.

Barton, J.; Collins, A. (Eds.). Portfolio assessment: a handbook for educators. Menlo Park, CA: Innovative Learning Publications, 1997.

Belleï, C. The public-private school controversy in Chile. In: Chakrabarti, R.; Peterson, P. (Eds.). School choice international: exploring public-private partnerships. Cambridge, MA: MIT Press, 2009.

BRACEY, G. The war against American's public schools: privatizing schools, commercializing education. Boston: Allyn \& Bacon, 2002.

Carnoy, M. National voucher plans in Chile and Sweden: did privatization reforms make for better education? Comparative Education Review, Chicago: University of Chicago Press, v. 42(3), p. 309-337, 1998.

Globalization and educational reform: what planners need to know. Paris: UNESCO, 1999. Disponível em: <http://www.unesco.org/iiep>. Acesso em: 20 out. 2014.

Rothstein, R.; Beneviste, L. All else equal: are public and private schools different? New York: Routledge Falmer, 2003.

Chase, B. Funding fairy tales: it takes more than tuition money to help poor children succeed. Washington Post, Washington, DC: [s.n.], 24 sep. 2000. 
Chubв, J.; Moe, T. Politics, markets, and America's schools. Washington, DC: Brookings Institute, 1990.

Coleman, J.; Hoffer, T.; Kilgore, S. High school achievement: public, catholic, and private schools compared. New York: Basic Books, 1982.

Darling-Hammong, L.; Bransford, J. (Eds.). Preparing teachers for a changing world: what teachers should learn and be able to do. San Francisco: Jossey-Bass, 2005.

EUA General Accounting Office (GAO). Public schools: comparison of achievement results for students attending privately managed and traditional schools in six cities. Report to the Chairman, Committee on Education and the Workforce, House of Representatives, oct. 2003.

FABRICANT, M.; FIne, M. Charters schools and the corporate makeover of public education: what's at stake? New York: Teachers College Press, 2012.

Fox, J.; Brown, D. The struggle for accountability: the World Bank, NGOs and Grassroots Movements. Cambridge, Mass: MIT Press, 1998.

Gilbert, C.; Vines, D. The World Bank: structures and policies. Cambridge: Cambridge University Press, 2000.

Hahnel, R. Economic justice and democracy: from competition to cooperation. New York: Routledge, 2005.

HANusheк, E. The economics of schooling: production and efficiency in public schools. Journal of Economic Literature, Pittsburgh, PA: AEA, XXIV, p. 1.141-1.177, 1986.

. What if there are no "best practices?". Scottish Journal of Political Economy, Scotland: SES, v. 51 (2), p. 156-172, may 2004.

Howell, W.; Wolf, P.; Peterson, P.; Campbell, D. (2000). Test-score effects of school vouchers in Dayton, Ohio, New York City, and Washington, DC: evidence from randomized field trials. In: American Political Science Association. Washington, DC, sept. 2000, p. 19-22.

Jordan, M.; Hackвart, M. Performance budgeting and performance funding in the States: a status assessment. Public Budgeting and Finance, New Jersey: Wiley-Blackwell, v. $19(1)$, p. $68-88,1999$.

Klay, W. Management through budgetary incentives. Public Productivity and Management Review, New York: M. E. Sharpe, v. 41, p. 59-71, 1987.

KleEs, S. A quarter century of neoliberal thinking in education: misleading analyses and failed policies. Globalization, Societies, and Education, Reino Unido: Routledge, v. 6, n. 4, p. 311-348, 2008.

. Review of School Choice International: Exploring Public-Private Partnerships By Rajashri Chakrabarti and Paul Peterson. Globalization, Societies, and Education, Reino Unido: Routledge, v. 8(1), p. 159-166, 2010.

; Samoff, J.; Stromeuist, N.(Eds.). The World Bank and education: critiques and alternatives. Boston: Sense, 2012.

Kонn, A. The case against standardized testing: raising the scores, ruining the schools. Portsmouth, NH: Heinemann, 2000. 
Kozol, J. Savage inequalities: children in America's schools. New York: Harper Perennial, 1992.

Fire in the ashes: twenty-five years among the poorest children in America. New York: Crown, 2012.

Krueger, A.; Zhu, P. Inefficiency, subsample selection bias, and nonrobustness: a response to Paul E. Peterson and William G. Howell. American Behavioral Scientist, California: Sage, v. 47(5), p. 718-728, 2004.

Levin, H. Educational vouchers: effectiveness, choice, and costs. Journal of Policy Analysis and Management, New Jersey: Wiley-Blackwell,v. 17, p. 373-392, 1998.

. Our schools in the year 2030 Forum: How Will They be Different? Education Next, Cambridge, MA: [s.n.], 2006. Disponível em: <www.educationnext.org/20062/>. Acesso em: 20 out. 2014.

Lockheed, M.; Jimenez, E. Public and private schools overseas: contrasts in organization and effectiveness. In: Fuller, B.; Elmore, R. (Eds.). Who chooses? Who loses? New York: Teachers College Press, 1996. p. 138-153.

Lubienski, C. The relationship of competition and choice to innovation in educational markets: a review of research on four cases. Occasional Paper, National Center for the Study of Privatization in Education, Teachers College, Columbia University, New York, NY, 2001. Disponível em: <www.ncpse.org>. Acesso em: 20 out. 2014.

Lubienski, S.; Lubienski, C. School sector and academic achievement: a multilevel analysis of naep mathematics data.American Educational Research Journal, Washington, DC: Sage; AERA,v. 43(4), p. 651-698, 2006.

Machin, S.; Wilson, J. Public and private schooling initiatives in England. In: Chakrabarti, R.; Peterson, P. (Eds.). School choice international: exploring public-private partnerships. Cambridge, MA: MIT Press, 2009.

Malen, B.; Croninger, R.; Muncey, D.; Redmond Jones, D. Reconstituting schools: testing the theory of action. Education Evaluation and Policy Analysis, Washington, DC: AERA, v. 24(2), p. 113-132, 2002.

Marphatia, A.; Archer, D. Contradicting commitments: how the achievement of Education for All is being undermined by the International Monetary Fund. London: Global Campaign for Education and ActionAid International, sept. 2005.

Merril Lynch. Scholarship builder. [s.1.], 2000. Disponível em: <http://www.ml.com/ reporters/scholarshipbuilder>. Acesso em: 20 out. 2014.

Metcalf, K. Advocacy in the guise of science. Education Week, Bethesda, MD: Editorial Projects im Education, 23 sept. 1998.

Miller, G.; Hildreth, B. W.; Rabin, J. Performance-based budgeting. Boulder, CO: Westview Press, 2001.

Molnar, A. Calculating the benefits and costs of for-frofit public education. Education Policy Analysis Archives, Washington, DC: ASU, v. 9(15), 24 apr. 2001. 
Mundy, K.; Murphy, L. Transnational advocacy, global civil society? Emerging evidence from the field of education. Comparative Education Review, Chicago: University of Chicago Press, v. 45(1), p. 85-126, feb. 2001.

Myers, D.; Pfleiderer, J. Voucher claims of success are premature in New York City. Press release from Mathematica, 15 sept. 2000.

Nichols, S.; Glass, G.; Berliner, D. High-stakes testing and student achievement: problems for the no child left behind act. Education Policy Studies Laboratory, Arizona State University, sept. 2005. Disponível em: <http://edpolicylab.org>. Acesso em: 20 out. 2014

Psacharopoulos, G.; Woodhall, M. Education for development: an analysis of investment choices. New York: Oxford University Press, 1985.

Reimers, F. (Ed.). Unequal schools, unequal chances: the challenges to equal opportunity in the Americas. Cambridge, MA: Harvard University Press, 2000.

Renzulli, L. A.; Roscigno, V.J. Charter school policy, implementation, and diffusion across the United States. Sociology of Education, Albany, NY:Sage; ASA, v. 78, p. 344-366 , oct. 2005.

Saltman, K. Collateral damage: corporatizing public schools - a threat to democracy. Lanham, MD: Rowman \& Littelfield, 2000.

Schorr, E. Within our reach. New York: Anchor Press, 1990.

Snyder, T.; Dillow, S.; Hoffman, C. Digest of education statistics 2008 (NCES 2009-020). National Center for Education Statistics, Institute of Education Sciences, U.S. Department of Education, Washington, DC, 2009.

Unesco. EFA Global monitoring report. youth and skills: putting education to work. Paris: UNESCO, 2012.

ViAdero, D. Researcher at center of storm over vouchers. Education Week, Bethesda, MD: Editorial Projects in Education, aug. 5, 1998.

Wolf, P.; Gutmann, B.; Puma, M.; Kisida, B.; Rizzo, L.; Eissa, N. (2009). Can educational vouchers solve the problem of low achievement in Washington DC? - results of a three year experiment. National Center for the Study of Privatization in Education, occasional Paper n. 174, 2009.

World Bank. Education sector strategy. Washington, DC: The World Bank; Human Development Network, 1999.

. World Development Report 2004: making services work for poor people. Washington, DC: World Bank, 2004.

. Learning for all: investing in people's knowledge and skills to promote development. Washington, DC: World Bank, 2011. 


\section{SOBRE OS AUTORES}

Steven J. Klees é doutor em economia e política pública pela Stanford University (Estados Unidos). Professor da University of Maryland (Estados Unidos).

E-mail: sklees@umd.edu

D. Brent Edwards JR. é doutor em política de educação internacional pela University of Maryland (Estados Unidos). Professor da Drexel University (Estados Unidos).

E-mail:dbrente@gmail.com

Recebido em julho de 2014

Aprovado em julbo de 2014 